http://jmscr.igmpublication.org/home/ ISSN (e)-2347-176x ISSN (p) 2455-0450 crossref DOI: https://dx.doi.org/10.18535/jmscr/v7i11.78

\author{
(D) Journal Of Medical Science And Clinical Research \\ IGM Publication \\ An Official Publication of IGM Publication
}

\title{
Clinical patterns and Epidemiological characteristics of facial hyperpigmentation
}

\section{Authors \\ Dr Kirti Deo ${ }^{1}$, Dr Alisha ${ }^{2 *}$, Dr Mahendra Singh Deora ${ }^{3}$, Dr Pallavi Singh ${ }^{2}$, Dr Bhavika Shah ${ }^{2}$}

${ }^{1}$ Professor, Department of Dermatology, Dr D.Y Patil Medical College and Hospital, affiliated to Dr D.Y Patil Vidyapeeth University, Pune

${ }^{2} 3^{\text {rd }}$ year Post Graduate Resident, Department of Dermatology, Dr D.Y Patil Medical College and Hospital, affiliated to Dr D.Y Patil Vidyapeeth University, Pune

${ }^{3}$ Head of Department of Dermatology, Dr. D.Y Patil Medical College and Hospital, affiliated to Dr D.Y

Patil Vidyapeeth University, Pune

*Corresponding Author

\section{Dr Alisha}

Dr D.Y Patil Medical College and Hospital, affiliated to D.Y Patil Vidyapeeth University, Pune

\begin{abstract}
Background: Facial and neck pigmentations are the most cosmetically important. They are common in middle-aged women, and are related to endogenous (hormones) and exogenous factors (such as use of cosmetics and perfumes, and exposure to sun radiation). Several more or less well-defined clinical syndromes can be recognized, but many transitional forms defy classification. The majority of the world's population is brown-skinned, and an enormous amount of interest worldwide is focused on restoring hyperpigmented skin to its natural color by skin care specialists.

Methods: A Descriptive observational study is conducted among 323 patients of facial hyperpigmentation coming to outpatient Department of dermatology, venereology, leprosy of Dr. D.Y. Patil Medical College and Hospital, Pune. Detailed history and clinical findings were recorded in standard proforma. Necessary investigations were carried out whenever required and data was subjected to statistical analysis.

Results: We found 14 diseases mainly contributing to the cases of facial hyperpigmentation. Melasma being the most common, other causes of facial pigmentation, include post inflammatory hyperpigmentation, drug induced pigmentation, topical steroid damaged face, Riehl's melanosis, Perioral hyperpigmenttion, Periorbital hyperpimentation, ashy dermatosis and nevus of face.

Conclusion: Facial hypermelanosis is a clinical feature of a diverse group of disorders, the most common of which is melasma. It is important to have a comprehensive understanding and information on the clinicoepidemiological profile and etiological factors of various clinical entities of facial hyperpigmentation for better management of patients.
\end{abstract}

Keywords: Facial Hyperpigmentation, Melasma, Post inflammatory hyperpigmentation, Topical steroid damaged face, Drug induced hyperpigmentation.

\section{Introduction}

Since the beginning of human kind, the concept of beauty played a vital role in the existence. The ancient Greeks first described the gospel of beauty. The Greek philosophers Socrates and Plato were the first at attempting to define beauty. Uniform and fair skin colour is the essence of a vibrant skin. Our 
Indian society is obsessed with fair skin colour. Fairness has been an indicator of social status across many societies. Dark-skinned men and women are often subjected to discrimination and judged harshly. Hordes of youngsters are spending a lot on fairness creams, trying hard to lighten their skins. Any mottling in the skin tone has a negative connotation among different cultures and therefore, pigmentary disorders of the skin are a great concern to the patient. Unlike most internal illnesses, skin diseases especially those on face are often visible to others and they lead to significant psychological consequences, thus explaining the growing importance of these disorders. ${ }^{[1]}$

The colour of normal skin comes from a mixture of pigments, of which the predominant is melanin. Disorders of hyperpigmentation comprise a large group of skin conditions characterized by an increase in melanin production, increase in density of active melanocytes, abnormal melanin distribution and/or deposition of exogenous pigments.

Apart from melanin the surrounding keratinocytes, extracellular matrix proteins and fibroblasts in the dermis also contributes to cutaneous homeostasis. Many autocrine/paracrine secreted factors and cell adhesion mechanisms which involve both epidermal and dermal constituents determine constitutive skin pigmentation. Pigmentary disorders occur whenever they are dysregulated. Increased expression of such mediators and their specific receptors frequently lead to hyperpigmentary conditions, such as in melasma and in solar lentigo. ${ }^{[2]}$

Facial hyperpigmentation is a common dermatological complaint, which appears in a number of heterogeneous disorders.

They can either be congenital like nevus of Ota, lentiginosis, cafe au lait macules or can be acquired e.g. melasma, seborrheicmelanosis, post inflammatory hyperpigmentation, periorbital hyperpigmentation, drug induced hyperpigmentation, topical steroid damaged face, lichen planus pigmentosus, perioral hyperpigmentation, Riehl's melanosis, ashy dermatosis etc
This study is conducted to study the clinicoepidemiological characteristics of facial hyperpigmentation, to assess the roles of various factors in the pathogenesis of facial hyperpigmentation

\section{Aim}

To determine the clinico-epidemiological trends of facial hyperpigmentation.

\section{Methodology}

A Descriptive observational study was conducted among 323 patients of facial hyperpigmentation coming to outpatient clinic of Department of Dermatology, Dr. D.Y. Patil Medical College and Hospital, Pune.

A questionnaire was used to record the demographic details of all patients including the age of onset, duration of disease, site of onset of pigmentation, rate of progression, associated symptoms, and family history. Information was also noted regarding any precipitating factors, use of cosmetics, drug intake prior to the onset and associated cutaneous or systemic diseases. A detailed general physical examination was done. Local examination of facial pigmentation was done.

\section{Inclusion Criteria}

All patients of facial hyperpigmentation reporting to OPD, who consented to participate, were included in the study.

\section{Exclusion Criteria}

Patients not willing to participate in the study. The statistical analysis was performed using the SPSS software version 20.0. Continuous variables were presented as measures of central tendency such as mean and standard deviation and categorical variables were presented as absolute numbers and percentage. Categorical variables were analysed using the Chi square test. For all statistical tests, a pvalue less than 0.05 was taken to indicate a significant difference

\section{Results}

Age and sex wise distribution of cases is given in Table 1 and 2 respectively. 
Table: 1

\begin{tabular}{|l|c|c|}
\hline Age (Years) & No of cases & Percentage \\
\hline$\leq 20$ & 6 & 1.9 \\
\hline $21-30$ & 159 & 49.2 \\
\hline $31-40$ & 116 & 35.9 \\
\hline $41 \&$ above & 42 & 13.0 \\
\hline Total & 323 & 100.0 \\
\hline
\end{tabular}

Table: 2

\begin{tabular}{|l|c|c|}
\hline Sex & No of cases & Percentage \\
\hline Male & 87 & 26.9 \\
\hline Female & 236 & 73.1 \\
\hline Total & 323 & 100.0 \\
\hline
\end{tabular}

In our study, the duration of symptoms ranged from 1 month to 10 years. Two cases had pigmentation present since birth (Fig.1)

Fig.1 Bar digram showing duration of symptoms

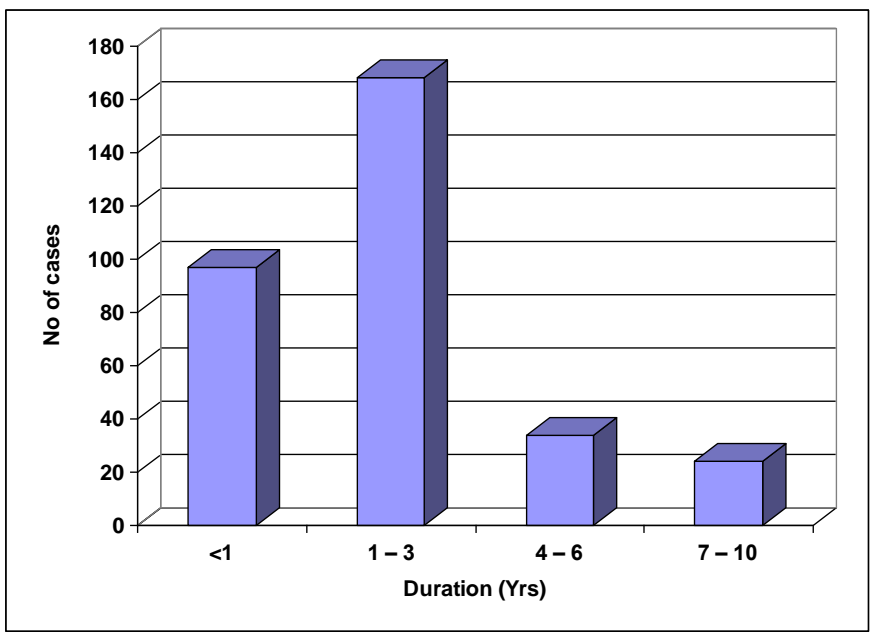

We found 14 diseases mainly contributing to the cases of facial hyperpigmentation. The most common cause being melasma in 108 cases (33.4\%) followed by post inflammatory hyperpigmentation (18.9\%), drug induced hyperpigmentation (7.7\%) and topical steroid damaged face in $21(6.5 \%)$ cases. (Table-3)

In our study history of sun exposure was present in 176 cases $(54.5 \%)$. (Fig. 2 )

Table: 3

\begin{tabular}{|l|c|c|}
\hline Disease & No of cases & Percentage \\
\hline Melasma inflammatory & 61 & 33.4 \\
\hline $\begin{array}{l}\text { Post induced } \\
\text { hyperpigmentation (PIH) }\end{array}$ & 25 & 18.9 \\
\hline $\begin{array}{l}\text { Drug } \\
\text { hyperpigmentation (DIH) }\end{array}$ & 21 & 6.7 \\
\hline $\begin{array}{l}\text { Topical steroid damaged } \\
\text { face (TSDF) }\end{array}$ & & 6.5 \\
\hline
\end{tabular}

\begin{tabular}{|l|c|c|}
\hline Perioral hyperpigmentation & 20 & 6.2 \\
\hline $\begin{array}{l}\text { Periorbital } \\
\text { hyperpigmentation }\end{array}$ & 17 & 5.3 \\
\hline Ashy dermatosis & 17 & 5.3 \\
\hline Seborrheic melanosis & 14 & 4.3 \\
\hline $\begin{array}{l}\text { Lichen planus pigmentosus } \\
\text { (LPP) }\end{array}$ & 10 & 3.1 \\
\hline Lentigines & 8 & 2.5 \\
\hline Freckles & 7 & 2.2 \\
\hline Riehl's melanosis & 5 & 1.5 \\
\hline Nevus of Ota & 4 & 1.2 \\
\hline $\begin{array}{l}\text { Perioral with periorbital } \\
\text { hyperpigmentation }\end{array}$ & 2 & .6 \\
\hline PIH with melasma & 2 & .6 \\
\hline Becker's nevus & 2 & .6 \\
\hline Total & 323 & 100.0 \\
\hline
\end{tabular}

Fig: 2 Pie digram showing history of sun exposure in cases.

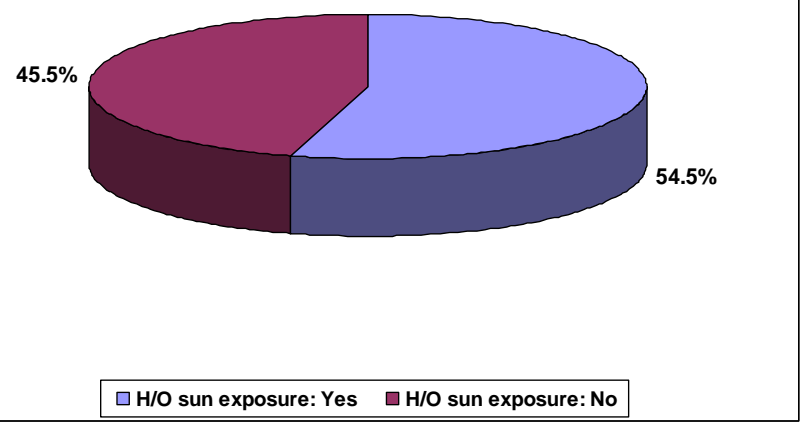

Cosmetic use was present in $52 \%$ cases of facial hyperpigmentation for variable period of time (Table: 4)

Table: 4

\begin{tabular}{|l|c|c|}
\hline Details of cosmetic used & No of cases & Percentage \\
\hline Fairness creams & 81 & 48.21 \\
\hline Steroid creams & 52 & 30.95 \\
\hline Ayurvedic creams & 29 & 17.26 \\
\hline Hair dye & 6 & 3.57 \\
\hline Total & 168 & 100 \\
\hline
\end{tabular}

Majority patients came with pigmentation all over the face (49.8) followed by cheeks (13.3\%), nose $(9.9 \%)$, around the mouth $(8 \%)$ and around eyes (6.2\%) (Table:5) 
Table: 5

\begin{tabular}{|l|c|c|}
\hline Sites & No of cases & Percentage \\
\hline All over face & 161 & 49.8 \\
\hline Cheeks & 43 & 13.3 \\
\hline Nose and cheeks & 32 & 9.9 \\
\hline Perioral & 26 & 8.0 \\
\hline Periorbital & 20 & 6.2 \\
\hline Ramus of mandible & 14 & 4.3 \\
\hline Forehead & 11 & 3.4 \\
\hline Cheeks and forehead & 10 & 3.1 \\
\hline Periorbital and perioral & 4 & 1.2 \\
\hline Chin & 2 & .6 \\
\hline Total & 323 & 100.0 \\
\hline
\end{tabular}

Out of 323 cases, 64 (19.8\%) gave history of taking drugs for different diseases. Out of these only 25 patients attributed their disease to specific drugs, which included 7 patients on MB-MDT for lepromatous leprosy and 6 on minocycline for acne. In melasma, 11 patients gave history of taking OCPs and other cases were on amiodarone and anti tubercular treatment (ATT). In other disorders the patients gave history of consumption of other drugs like anti-diabetic and anti-hypertensives for the associated conditions but the patients did not attribute the intake of drugs as a precipitating factor for melanosis. (Fig 3)

Fig: 3 Bar digram showing details of the drug taken

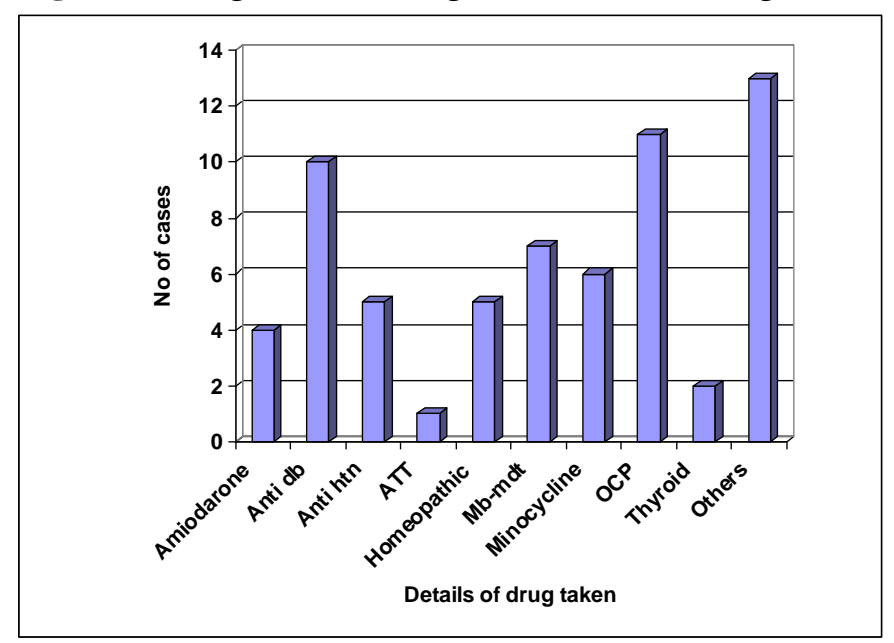

\section{Melasma}

As melasma was the most common condition (33.4\%), we studied further about its types, patterns and predisposing factors. Disease onset was commonest in the 2nd (44\%) decade followed by the 3 rd $(48 \%)$ decade of life. No case was reported beyond the $5^{\text {th }}$ decade.
It was common in females $(83.3 \%)$ in comparison to males $(16.7 \%)$. The most common pattern observed in our study was epidermal in $48.14 \%$, followed by mixed $(25.9 \%)$, dermal $(15.7 \%)$ and indeterminate in $10.1 \%$ of cases. (Table: 6 )

Table: 6

\begin{tabular}{|l|c|c|}
\hline Pattern & No of cases & Percentage \\
\hline Dermal & 17 & 15.7 \\
\hline Mixed & 28 & 25.9 \\
\hline Epidermal & 52 & 48.14 \\
\hline Indeterminate & 11 & 10.1 \\
\hline Total & 108 & 100 \\
\hline
\end{tabular}

Amongst the types of melasma, $45 \%$ cases were centrofacial followed by malar $(41 \%)$ and mandibular (12\%). (Table: 7$)$

Table.7

\begin{tabular}{|l|c|}
\hline Type of melasma & No of cases \\
\hline Centrofacial & 49 \\
\hline Malar & 45 \\
\hline Mandibular & 14 \\
\hline
\end{tabular}

\section{Discussion}

Hyperpigmentation of the skin is a common complaint among patients visiting dermatologists. In the skin of coloured population e.g. African, Asian, Native American, Middle Eastern and Hispanic backgrounds, facial hyperpigmentation is a common and growing concern when presenting to the dermatologists. These skin types are generally categorized as Fitzpatrick types IV- VI, and are more richly pigmented. An enormous amount of interest worldwide is just focused on restoring hyperpigmented skin to its natural colour by skin care specialists.

Several factors are responsible for the numerous hypermelanotic processes affecting the epidermis and/or dermis: hereditary, endocrine, nutritional, neoplastic, inflammatory, drugs, physical and chemical.

Due to their visibility, facial and neck pigmentations (cervicofacial pigmentations) are the most cosmetically important. Thus their clinicoepidemiological features are essential. We studied 323 patients of facial hyperpigmentation to 
determine the various clinical features and epidemiological factors in these patients.

\section{Age and sex distribution}

Among the 323 patients, majority belonged to age groups of $21-30$ years $(49.2 \%)$ followed by $31-40$ years $(35.9 \%)$. In both these age groups, females outnumbered males contributing to 206 and 69 cases respectively.

In the review article of Ana Perez et al. ${ }^{[3]}$, it has been quoted that facial hyperpigmentation is common in middle-aged women, and are related to endogenous (hormones) and exogenous factors (such as use of cosmetics and perfumes, and exposure to sun radiation) and also facial hyperpigmentation causes significant cosmetic disability which may be the reason for slightly more number of female patients seeking medical advice.

\section{Disorders presenting with facial hyperpigmentation}

The most common cause for facial hyperpigmentation in our study was melasma seen in $33.4 \%$ of cases, followed by post inflammatory hyperpigmentation (18.9\%) and drug induced

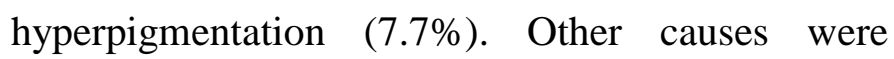
topical steroid damaged face $(6.5 \%)$, perioral hyperpigmentation $\quad(6.2 \%), \quad$ periorbital hyperpigmentation $(5.3 \%)$, ashy dermatosis $(5.3 \%)$, seborrheic melanosis (4.3\%), LPP (3.1\%), lentigines (2.5\%), freckles $(2.2 \%)$, Riehl's melanosis (1.5\%), $\& 2$ cases of Becker's nevus and nevus of Ota were also observed.

\section{Melasma}

$33.4 \%$ of cases in our study comprised melasma. The age range of melasma patients was 21-45 years with mean age being 32.42 years. This was in accordance with the study conducted by Arun Achar et $\mathrm{al}^{[4]}$, where the mean age was 33.45 years. Melasma is more common in women (79\%). $20.3 \%$ males were found to have melasma which was comparable to $19.87 \%$ in a study conducted by Arun Achar et al in India and $10 \%$ by Vazquez et al. $^{[5]}$

\section{Post inflammatory hyperpigmenttion}

The patients were in the age range of 18 to 54 years with a mean of 29.2 years. It was observed more commonly in females $(54.09 \%)$ as compared to males $(45.9 \%)$. This is in accordance to Nicole et $\mathrm{al}^{[6]}$ who mentioned that, PIH occurred with equal incidence in both sexes.

\section{Drug induced hyperpigmentation}

Drug-induced pigmentation represents $7.7 \%$ of all cases of acquired hyperpigmentation. Patients were in the age range of 24-46 years with mean age of 33.48 years and majority of patients were females $(56 \%)$. History of exacerbation of pigmentation on sun exposure was seen in 15 cases $(60 \%)$. All the patients in our study had diffuse pigmentation prominent on sun exposed areas and the pigmentation varied from erythematous to violaceous-brown color.

\section{Topical steroid damaged face}

It constituted $6.5 \%$ of the cases, of which $80.9 \%$ were females and $19 \%$ were males. Patient belonged to age range of 23-45 years with mean age of 31 years. Majority of the patients belonged to age group 21-30 years which was similar to study conducted by Dayamay pal et al. ${ }^{[7]}$ and Saraswat et al. $^{[8]}$

\section{Perioral hyperpigmentation}

It was seen in $6.2 \%$ of the cases. Patients were in the age range of 23-47 years with mean age of 31.75 years. It was seen mainly in the females (95\%). 6 patients gave history of use of topical corticosteroids for variable period of time. It was associated with burning and itching in 8 cases

\section{Periorbital hyperpigmentation}

In our study, it constituted $5.3 \%$ of cases of facial hyperpigmentation. Out of 17 cases, 2 (11.7\%) were males and $15(88.2 \%)$ females. Patients were in the age group of range 17-39 years with a mean age of 31.1 years which is in contrast to study conducted by Harneet Ranu et al. ${ }^{[9]}$ in Singapore who observed a male prepordance $(62.6 \%)$ and mean age of 26.4 
years. This can be attributed to geographic and racial differences.

\section{Ashy dermatosis}

It was seen in $5.3 \%$ of the cases. Patients were in the age range of 23-44 years with mean age of 30.8 years which was little lower compared to study of Vega et al where mean age was 33.6 years. ${ }^{[10]}$ It was seen more in females (52\%) compared to males (48\%) which was similar to study conducted by Vega et al.

\section{Lichen planus pigmentosus}

It constituted $3.1 \%$ of patients in our study. Bhutani et $\mathrm{al}^{[11]}$ reported $4.1 \%$ incidence of LPP in his study which is almost the same. It usually starts in the third to sixth decade of life. In our study patient belonged to age range of 34-53 years with mean age of 45.4 years which was similar to earlier studies conducted by Bhutani et al \& Vega et al. In our study the distribution of cases was equal among males and females which was in accordance to Bhutani et al., who observed no difference in sex distribution in their patients while Vega et al reported a male preponderance.

\section{Seborrheic melanosis}

It constituted $4.3 \%$ of the cases. Patients were in the age range of 25-45 years with a mean age of 34.28 years. In our study it was found more common in females (57\%) as compared to males (43\%). 8 patients also gave history of associated itching.

\section{Freckles}

It constituted $2.2 \%$ of the cases. Patients were in the age range of 24-55 years with mean age of 40 years. It was seen only in females in our study.

\section{Lentigines}

It constituted $2.5 \%$ of the cases. Patients were in the age range of 21-26 years with mean age of 23.5 years. It was seen only in females in our study. Duration of symptoms ranged from 5-10 years. In all patients it started at adolescent and was progressive in nature.

\section{Riehl's melanosis}

In constituted $1.5 \%$ of cases. Patients were in the age range of $42-48$ years with mean age of 45.6 years and more common in males, observed in $60 \%$ cases. All the cases had history of cosmetic use for a mean duration of 3 years and the various cosmetics used were fairness creams, ayurvedic creams, hair dye and steroid creams. Rorsman $\mathrm{H}^{[12]}$ also stated that the commonest cause was sensitizing chemicals in cosmetics. Itching was present in 3 cases $(60 \%)$.

\section{Nevus of Ota}

It constituted $1.2 \%$ of the cases. $50 \%$ had this disorder from birth and rest developed at puberty which was similar to a study conducted by Kopf et al. In our study it was found more common in females $(75 \%)$ similar to Kopf et al study where it was found in $80 \%$ females. ${ }^{[13]}$

\section{Becker's nevus}

It constituted $0.6 \%$ of the cases. Patients were in the age range of 21-24 years with mean age of 22.25 years. In our study it was found only in males.

\section{Conclusion}

Facial hyperpigmentation is a clinical feature of a diverse group of disorders. It is found most commonly in females of middle aged groups. The most common cause of facial hyperpigmentation is melasma. Other common causes are post inflammatory hyperpigmentation, drug induced hyperpigmentation, topical steroid damaged face. The incidence of topical steroid damaged face is increasing because of the increased use of fairness creams and over the counter creams.

The treatment of facial hyperpigmentation is still challenging. It is important to have a comprehensive understanding and information on the clinicoepidemiological and etiological factors of various clinical entities of facial hyperpigmentation for better management of patients.

Conflict of Interest: No conflict of interest. Financial Resources: No funding sources 


\section{References}

1. Hassan I, Aleem S, Bhat YJ, Anwar P. A clinicoepidemiological study of facial melanosis. Pigment Int. 2015;2:34-40.

2. Bastonini E, Kovacs D, Picardo M. Skin pigmentation and pigmentary disorders: focus on epidermal/dermal cross-talk. Annals of dermatology. 2016 Jun 1;28(3):279-89.

3. Ana Pérez-Bernal, Miguel A, Muñoz-Pérez, Camacho F. Management of Facial Hyperpigmentation. Am J Clin Dermatol. 2000 Sep-Oct;1(5):261-8.

4. Achar A, Rathi SK. Melasma: A clinicoepidemiological study of 312 cases. Indian J Dermatol. 2011;56:380-382.

5. Vazquez M, Maldonado H, Benaman C et al. Melasma in men: a clinical and histologic study. Int J Dermatol. 1988;27(1):25-27.

6. Nicole L. Lacz, Janet Vafaie, Nadia I. Kihiczak, $\quad$ Robert A.Schwartz. Postinflammatory hyperpigmentation: a common but troubling condition. International Journal of Dermatology. 2004;43:362-5

7. Pal D, Biswas P, Das S, De A, Sharma N, Ansari A. Topical steroid damaged/dependent face (TSDF): A study from a tertiary care hospital in Eastern India. Indian J Dermatol 2018;63:375-9

8. Saraswat A, Lahiri K, Chatterjee M, Barua S, Coondoo A, Mittal A, et al. Topical corticosteroid abuse on the face: A prospective, multicenter study of dermatology outpatients. Indian J Dermatol Venereol Leprol 2011;77:160-6.

9. Ranu H, Thng S, Goh BK, Burger A, Goh CL. Periorbital hyperpigmentation in Asians: an epidemiologic study and a proposed classification. Dermatol Surg. 2011Sep;37(9):1297-1303.

10. Vega ME, Waxtein L, Arenas R et al. Ashy dermatosis and lichen planus pigmentosus: a clinicopathologic study of 31 cases. Int $\mathbf{J}$ Dermatol.1992;31: 90-94
11. Bhutani LK, Bedi TR, Pandhi RK, Nayak NC. Lichen planus pigmentosus. Dermatologica. 1974;149:43-50.

12. Rorsman H. Riehl's melanoses. Int J Dermatol. 1982 Mar;21(2):75-8.

13. Kopf AW, Weidman AI: Nevus of Ota. Arch Dermatol 1962;85:195-208. 